20. Гадзяцкая О.С., Крайнов Д.А. Энеолитическое поселение Стрелка I в бассейне р. Клязьма // Российская археология. 2002. № 2. С. 111-131.

21. Сидоров В.В. Манок - музыкальный инструмент эпохи неолита // Народные музыкальные инструменты и инструментальная музыка. Ч. 1. М., 1987. C. $157-163$.

22. Мачинский А.В. Древняя эскимосская культура на Чукотском полуострове // Краткие сообщения Института истории материальной культуры. 1941. Вып. IX. C. 80-90.

23. Гурина Н.Н. Рыболовство и морской промысел на Кольском полуострове // Рыболовство и морской промысел в эпоху мезолита - раннего металла. Л.: Наука, 1991. С. 164-181.

24. Сахалинский областной краеведческий музей [Электронный ресурс] // http://special.sakhalinmuseum.ru.

25. Winged Object (harpoon butt) [El. resource] // Brooklyn Museum. - https://brooklynmuseum.org/ opencollection/objects/89599.

26. Крайнов Д.А., Зайцева Г.И., Костылёва Е.Л., Уткин А.В. Абсолютная хронология Сахтышских стоянок // Археологические памятники Волго-Клязьминского междуречья. Иваново, 1991. Вып. 5. С. 33-42.

27. Костылёва Е.Л., Уткин А.В. Хронология погребального обряда волосовской культуры на терри- тории Верхнего Поволжья и Волго-Окского междуречья // Труды II (XVIII) Всероссийского археологического съезда в Суздале. М., 2008. Т. I. С. 230-233.

28. Костылёва Е.Л., Мацане А. Орудия рыбной ловли из ритуальных «кладов» волосовской культуры со стоянки Сахтыш II Центральной России // Стратегии жизнеобеспечения в каменном веке, прямые и косвенные свидетельства рыболовства и собирательства: мат-лы междунар. конф., посв. 50-летию В.М. Лозовского / под ред. О.В. Лозовской, А.А. Выборнова и Е.В. Долбуновой. СПб.: ИИМК РАН, 2018. C. $144-148$.

29. Костылёва Е.Л., Уткин А.В. Проблема пространственно-хронологического соотношения поселений и могильников волосовской культуры (по материалам поселений Сахтыш II, IIA и VIII) // Археология озерных поселений IV-II тыс. до н.э.: хронология культур и природно-климатические ритмы: мат-лы междунар. конф., посв. полувековому исследованию свайных поселений на северо-западе России. СанктПетербург, 13-15 ноября 2014 г. СПб.: Изд-во ООО «Периферия». С. 179-183.

30. Никитин В.В. На грани эпохи камня и металла. Средневолжский вариант волосовской культурноисторической общности. Йошкар-Ола, 2017. 765 c.

\title{
CORACOID ARTEFACTS AND FISHING IMPLEMENTS OF THE VOLOSOVO CULTURE RITUAL «HOARDS» FROM SITE SAKHTYSH-II (CENTRAL RUSSIA)
}

(C) 2018

Kostyleva Elena Leonidovna, candidate of historical sciences, associate professor of Russian History Department Ivanovo State University (Ivanovo, Russian Federation)

Matsane Aiya, postgraduate student of Historical Faculty University of Gothenburg (Gothenburg, Kingdom of Sweden)

Abstract. Sakhtysh II burial ground (Central Russia) belongs to the final stage of the Eneolithic Volosovo culture evolution. The Upper-Volga expedition IA RAS conducted the research there during 1960-1980. About twenty ritual «hoards» were discovered at Sakhtysh II consisting of artifacts clusters with traces of fire exposure. Among them there is a variety of fishing tools: serrated edges, harpoons, fishing hooks. We believe that the coracoid artefacts made of bone, the purpose of which is still debated, are also harpoons. The variety of the fishing tools forms allow us to speak about the specialization in fishing. Time of use of these «hoards» is based on coal samples from the ritual hearths which have been determined by radiocarbon dates: $3820 \pm 40,3900 \pm 40,4190 \pm 50 \mathrm{BP}$ (Le-2617, 2613, 2615). However, dating of animal bones (bear and badger) from two «hoards» (№ 9 and 11) in 2017 at the Belfast laboratory provided new AMS dates: $4730 \pm 41$ and $4445 \pm 37$. The significant difference between new and previous dates may depend on the reservoir effect, due to the fact that the diet of these omnivorous animals included fish as well as the fact that these two «hoards» were located outside the main ritual areas, belonging to an earlier time.

Keywords: Central Russia; Ivanovo Region; Eneolithic; Volosovo culture; Sakhtysh-II burial ground; ritual hoards; fishing tools; fishing hooks; harpoons; coracoid artefacts of unknown purpose; radiocarbon dates; problem of dates validity; reservoir effect.

УДК 902.652

DOI 10.24411/2309-4370-2018-14208

Статья поступила в редакцию 30.08.2018

\section{СТАТИСТИЧЕСКАЯ МОДЕЛЬ РАДИОУГЛЕРОДНОЙ ХРОНОЛОГИИ НЕОЛИТИЧЕСКИХ ПАМЯТНИКОВ ЛЕСОСТЕПНОГО ЗАВОЛЖЬЯ}

(C) 2018

Ставицкий Владимир Вячеславович, доктор исторических наук,

профессор кафедры всеобщей истории и обществознания

Пензенский государственный университет (2. Пенза, Российская Федераџия)

Аннотация. В статье рассматривается хронология памятников раннего неолита лесостепного Заволжья, которая опирается на радиоуглеродные определения, полученные по фрагментам керамики. Радиоуглеродные даты по памятникам елшанской и средневолжской культур собраны в две таблицы. В них графически представлен вероятностный интервал для каждой даты. За условную статистическую единицу принят хронологический интервал продолжительностью 125 лет. На основе статистических данных автором построены 
графики, которые отражают частоту встречаемости дат по периодам продолжительностью 250 лет. По памятникам елшанской культуры наибольшая концентрация радиоуглеродных дат наблюдается на хронологическом отрезке 5875-5250 cal ВC (39\% всех дат). Вдвое меньше дат зафиксировано на отрезке 4750-4500 cal ВС (21\%). Только 12\% радиоуглеродных дат приходится на интервал 6750-6250 cal ВС, который относится исследователями к периоду формирования елшанских древностей. На наш взгляд, елшанская культура не могла существовать в неизменном виде столь продолжительное время. Столь значительный разброс во времени, видимо, объясняется несовершенством метода датирования и наличием «резервуарных эффектов» различного рода. Елшанская культура, вероятно, существовала в период 5875-5250 cal ВС. На заключительном этапе бытования елшанских древностей (5500-5250 cal BC) на их основе происходит сложение памятников средневолжской культуры.

Ключевые слова: ранний неолит; елшанская культура; средневолжская культура; лесостепное Заволжье; радиоуглеродная хронология; «резервуарный эффект»; неолитическая керамика; статистическая модель; периодизация елшанских древностей; верификация; калиброванные даты; сакральная керамика; археологический контекст.

В конце прошлого столетия было опубликовано 7 радиоуглеродных дат, полученных по створкам речных раковин, скопления которых были зафиксированы в культурном слое стоянок елшанской культуры Чекалино IV и Лебяжинка IV. Согласно этим датам формирование культурного слоя елшанских памятников укладывалось в период с 8990 по 7940 ВР [1, c. 15-43]. Столь древнему возрасту елшанских древностей исследователи нашли подтверждение в радиоуглеродном определении находки кости из материалов Ивановской многослойной стоянки, дата которой соответствовала значению $8020+90$ ВР. Вскоре еще одна дата была получена по раковинам, собранным в слое Ильинской стоянки, и ее значение $8510 \pm 60$ ВР укладывалось в тот же хронологический период [2, с. 148-162]. Благодаря этой серии дат в литературе утвердилась точка зрения о том, что елшанские памятники являются древнейшими неолитическими стоянками Русской равнины $[3$, с. 209 $214 ; 4$, с. 147-176].

Достоверность радиоуглеродных определений, полученных по раковинам, была оспорена А.В. Вискалиным в докладе, прочитанном на Тверской конференции весной 2003 г., где им было высказано предположение о том, что раковины речных моллюсков не были принесены на стоянки человеком, а попали туда в результате разливов реки. Следовательно, раковины могли оказаться на памятнике в период, предшествующий образованию культурного слоя [5, с. 260-264]. Впрочем, после получения двух радиоуглеродных дат по елшанской керамике стоянки Усть-Ташелка $7680 \pm 190$ ВР и $7810 \pm 190$ ВР [6, с. 413] недостоверность ряда «младших» дат, полученных по раковине, уже не представлялась столь очевидной. Однако в скором времени исследователи пришли к выводу, что датировка по раковинам может значительно удревнять возраст памятника, поскольку раковины подвержены резервуарном эффекту, суть которого заключается в том, что они могут поглощать из почвенных вод более древний углерод [7, с. 39-47].

Новый этап в изучении хронологии елшанских древностей был связан со значительной серией дат (более 50), которые усилиями А.А. Выборнова были получены за последнее десятилетие в киевской радиоуглеродной лаборатории и ряде других организаций по елшанской керамике. Оперируя этими определениями, А.А. Выборнов пришел к выводу, что начало развития елшанских древностей маркирует дата Ивановской стоянки $7930 \pm 90$ ВР, полученная по наиболее архаичной керамике, не содержащей шамота, с которой согласуется дата по кости $8020 \pm 90$ ВР с этого же памятника. А дальнейшее развитие данной керамической традиции иллюстри- руют две даты, полученные по остродонной керамике с шамотом $7780 \pm 90$ ВР и $7680 \pm 90$ ВР Ивановской стоянки, которые укладывались примерно в тот же хронологический интервал, что и даты по плоскодонной керамике стоянки Усть-Ташелка [8, с. 128].

Однако по мере накопления дат по керамике оказалось, что для них характерен довольно значительный разброс, как в сторону удревнения хронологии (чаще), так и ее омоложения (реже). В литературе неоднократно поднимались вопросы, в которых обсуждались возможные причины, влияющие на результаты радиоуглеродного датирования, а также возможные способы обработки керамических образцов, позволяющие данные причины минимизировать $[9$, с. $64-71 ; 10$, с. 37].

В итоге А.А. Выборновым была выстроена развернутая система хронологии елшанских древностей, одним из постулатов которой является предположение о различной степени валидности радиоуглеродных дат в зависимости от их соответствия археологическому контексту. Исходя из данного положения, период появления елшанской культуры на территории Самарского Поволжья был определен временем $6500 \mathrm{cal} \mathrm{BC}$, а на Средней Суре и Мокше - 6200 cal ВC [11, с. 69]. Подобный подход к интерпретации радиоуглеродных дат наиболее эффективен в условиях, когда их число ограничено. Однако к настоящему времени накопилось такое количество радиоуглеродных определений, которое позволяет верифицировать достоверность датировок исходя из их среднестатистических величин.

Для этой цели автором была составлена хронологическая таблица (табл. 1), в которой были учтены даты, полученные по елшанской керамике лесостепного Заволжья, т.е. той территории, культурная принадлежность памятников которой ни у кого не вызывает вопросов. Распределение радиоуглеродных даты в таблице представлено графически по периодам продолжительностью в 125 лет. Каждый период представляет собой одну статистическую единицу. Для того чтобы уравнять значимость «коротких» и «длинных дат», для каждой из них был вычислен коэффициент сопряженности. Его величина зависела от того, сколько периодов охватывал калиброванный интервал радиоуглеродной даты, на число которых каждая дата делилась. У дат с наибольшими погрешностями этот коэффициент составлял 0,14 (единица, деленная на 8 периодов), с наименьшими - 0,5 (единица, деленная на 2). После чего с учетом данных коэффициентов была подсчитана частота встречаемости радиоуглеродных дат для интервалов протяженностью в 250 лет, информация о которой для наглядности была переведена в проценты и представлена в виде графика. 
Ставицкий В.В.

Статистическая модель радиоуглеродной хронологии неолитических...

07.00.00 - исторические науки и археология

Таблица 1 - Радиоуглеродные даты елшанских памятников, выполненные по фрагментам керамики

\begin{tabular}{|c|c|c|c|c|c|c|c|c|c|c|c|c|c|}
\hline cal BC & $\begin{array}{l}7250- \\
7000\end{array}$ & $\begin{array}{l}7000- \\
6750\end{array}$ & $\begin{array}{l}6750- \\
6500\end{array}$ & $\begin{array}{l}6500 \\
6250\end{array}$ & $\begin{array}{c}6250- \\
6000\end{array}$ & \begin{tabular}{|c|}
$6000-$ \\
5750
\end{tabular} & \begin{tabular}{|c|}
$5750-$ \\
5500
\end{tabular} & \begin{tabular}{|c|}
$5500-$ \\
5250
\end{tabular} & \begin{tabular}{|c|}
$5250-$ \\
5000 \\
\end{tabular} & $\begin{array}{c}5000- \\
4750\end{array}$ & $\begin{array}{c}4750- \\
4500\end{array}$ & $\begin{array}{c}4500- \\
4250\end{array}$ & $\begin{array}{r}4250 \\
4000\end{array}$ \\
\hline \multicolumn{14}{|c|}{ Чекалино IV } \\
\hline $7660 \pm 200$ & & $\mathrm{XX}$ & $\mathrm{XX}$ & $\mathrm{XX}$ & $\mathrm{x}$ & & & & & & & & \\
\hline $7127 \pm 130$ & & & & $\mathrm{x}$ & $\mathrm{xx}$ & $\mathrm{xx}$ & & & & & & & \\
\hline $5870 \pm 80$ & & & & & & & & & & $\mathrm{xx}$ & $\mathrm{xx}$ & & \\
\hline $5910 \pm 90$ & & & & & & & & & & $\mathrm{xx}$ & $\mathrm{xx}$ & & \\
\hline \multicolumn{14}{|c|}{ Лебяжинка IV } \\
\hline $6680 \pm 80$ & & & & & & & $\mathrm{xx}$ & & & & & & \\
\hline $6895 \pm 120$ & & & & & & $\mathrm{xx}$ & $\mathrm{x}$ & & & & & & \\
\hline $5970 \pm 80$ & & & & & & & & & $\mathrm{xx}$ & $\mathrm{xx}$ & $\mathrm{x}$ & & \\
\hline $6080 \pm 90$ & & & & & & & & & $\mathrm{xx}$ & $\mathrm{xx}$ & & & \\
\hline $5980 \pm 90$ & & & & & & & & & $\mathrm{xx}$ & $\mathrm{xx}$ & $\mathrm{x}$ & & \\
\hline $5850 \pm 120$ & & & & & & & & & & $\mathrm{xx}$ & $\mathrm{xx}$ & & \\
\hline \multicolumn{14}{|c|}{ Ильинка } \\
\hline $6740 \pm 70$ & & & & & & & $\mathrm{xx}$ & & & & & & \\
\hline $6680 \pm 70$ & & & & & & & $\mathrm{xx}$ & & & & & & \\
\hline $6760 \pm 90$ & & & & & & $\mathrm{x}$ & $\mathrm{xx}$ & & & & & & \\
\hline $6640 \pm 100$ & & & & & & & $\mathrm{xx}$ & $\mathrm{x}$ & & & & & \\
\hline $6940 \pm 90$ & & & & & & $\mathrm{xx}$ & $\mathrm{x} \mid$ & & & & & & \\
\hline $6820 \pm 150$ & & & & & & $\mathrm{xx}$ & $\mathrm{xx}$ & & & & & & \\
\hline $6807 \pm 70$ & & & & & & $x$ & $\mathrm{xx}$ & & & & & & \\
\hline \multicolumn{14}{|c|}{ Красный Городок } \\
\hline $6730 \pm 100$ & & & & & & $\mathrm{x}$ & $\mathrm{xx}$ & & & & & & \\
\hline $6550 \pm 130$ & & & & & & & $\mathrm{xx}$ & $\mathrm{xx}$ & & & & & \\
\hline $6677 \pm 100$ & & & & & & & $\mathrm{xx}$ & & & & & & \\
\hline \multicolumn{14}{|c|}{ Старая Елшанка II } \\
\hline $6820 \pm 80$ & & & & & & $\mathrm{x}$ & $\mathrm{xx}$ & & & & & & \\
\hline $6760 \pm 80$ & & & & & & $\mathrm{x}$ & $\mathrm{xx}$ & & & & & & \\
\hline $6480 \pm 80$ & & & & & & & $\mathrm{x}$ & $\mathrm{xx}$ & & & & & \\
\hline \multicolumn{14}{|c|}{ Ивановка } \\
\hline $7930 \pm 90$ & & $\mathrm{xx}$ & $\mathrm{x}$ & & & & & & & & & & \\
\hline $7780 \pm 90$ & & $\mathrm{xx}$ & $\mathrm{xx}$ & & & & & & & & & & \\
\hline $7680 \pm 90$ & & & $\mathrm{xx}$ & $\mathrm{x}$ & & & & & & & & & \\
\hline $7560 \pm 70$ & & & & $\mathrm{xx}$ & & & & & & & & & \\
\hline \multicolumn{14}{|c|}{ Нижняя Орлянка II } \\
\hline $5630 \pm 80$ & & & & & & & & & & & $\mathrm{x}$ & $\mathrm{x}$ & \\
\hline $5720 \pm 80$ & & & & & & & & & & & $\mathrm{xx}$ & $\mathrm{x}$ & \\
\hline $5660 \pm 150$ & & & & & & & & & & $\mathrm{x}$ & $\mathrm{xx}$ & $\mathrm{xx}$ & $\mathrm{x}$ \\
\hline \multicolumn{14}{|c|}{ Максимовка } \\
\hline I $6420 \pm 80$ & & & & & & & & $\mathrm{xx}$ & & & & & \\
\hline $6470 \pm 80$ & & & & & & & $\mathrm{x}$ & $\mathrm{xx}$ & & & & & \\
\hline \multicolumn{14}{|c|}{ Красный Яр VII } \\
\hline $6540 \pm 80$ & & & & & & & $\mathrm{x}$ & $\mathrm{x}$ & & & & & \\
\hline $6280 \pm 90$ & & & & & & & & $\mathrm{xx}$ & $\mathrm{xx}$ & & & & \\
\hline \multicolumn{14}{|c|}{ Большая Раковка II } \\
\hline $7790 \pm 200$ & $\mathrm{xx}$ & $\mathrm{xx}$ & $\mathrm{xX}$ & $\mathrm{xx}$ & & & & & & & & & \\
\hline $6894 \pm 120$ & & & & & & $\mathrm{xx}$ & $\mathrm{x}$ & & & & & & \\
\hline $6647 \pm 120$ & & & & & & & $\mathrm{xx}$ & $\mathrm{x}$ & & & & & \\
\hline $6310 \pm 90$ & & & & & & & & $\mathrm{xx}$ & $\mathrm{xx}$ & & & & \\
\hline $5770 \pm 90$ & & & & & & & & & & & $\mathrm{x}$ & $\mathrm{x}$ & \\
\hline $5610 \pm 90$ & & & & & & & & & & & $\mathrm{xx}$ & $\mathrm{XX}$ & \\
\hline $7613 \pm 120$ & & & $\mathrm{xx}$ & $\mathrm{xx}$ & & & & & & & & & \\
\hline \multicolumn{14}{|c|}{ Калмыковка } \\
\hline $6643 \pm 110$ & & & & & & & $\mathrm{xx}$ & $\mathrm{x} \mid$ & & & & & \\
\hline $\begin{array}{l}\text { Сумма датировок, } \\
\text { лаборатория СПб., \% }\end{array}$ & 5,07 & 4,15 & 8 & 17,3 & 4,15 & 19,6 & 32 & 5,07 & 0 & 1,31 & 2,62 & 2,62 & 1,31 \\
\hline $\begin{array}{l}\text { Сумма датировок, } \\
\text { лаборатория Киев, \% }\end{array}$ & 0 & 5,72 & 5,17 & 1,13 & 0 & 6,9 & 28,65 & 14,34 & 7,93 & 9,65 & 14 & 6,31 & 0 \\
\hline $\begin{array}{l}\text { Общая сумма датиро- } \\
\text { вок, \% }\end{array}$ & 0,53 & 3,47 & 5,16 & 5,24 & 2,12 & 7,90 & 21,32 & 10,16 & 4,69 & 6,06 & 8,98 & 4,43 & 0,34 \\
\hline
\end{tabular}

Примечание. Курсивом выделены даты петербургской лаборатории. 
По графику видно (рис. 1), что максимум дат (39\% всех значений) приходится на период 5875$5250 \mathrm{cal} \mathrm{BC}$, затем наблюдается видимый спад и новый максимум приходится на период 4750-4500 cal ВС (21\%). Еще одна (наименьшая по величине) группировка дат приходится на период 6750-6250 cal ВС $(12 \%)$. В монографии К.М. Андреева и А.А. Выборнова с ранней (12-ти процентной) группировкой дат связывается период становления и первоначального бытования елшанских древностей. Крайняя малочисленность дат, приходящихся на период 6250$5875 \mathrm{cal}$ ВC, объясняется ими либо оттоком населения вследствие аридизации климата, либо отсутствием исследованных стоянок, относящихся к данному интервалу. Концентрацию дат периода 5875-5250 cal ВС они связывают с развитым периодом елшанской культуры. Поздняя группировка дат признается К.М. Андреевым и А.А. Выборновым некорректной, поскольку они противоречат ранним датам, полученных с тех же самых памятников (Чекалино IV, Большая Раковка II) и кроме того «растягивают» существование культуры на две тысячи лет, что маловероятно [12, с. 82-87].

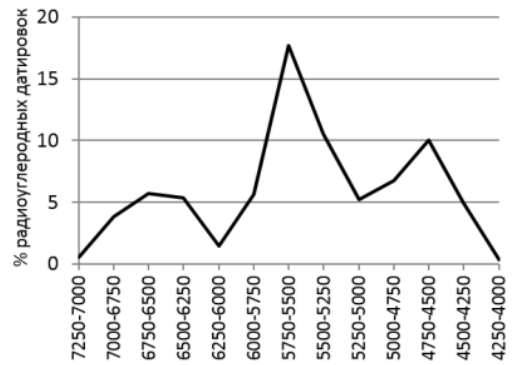

Рисунок 1 - График радиоуглеродных датировок керамики елшанской культуры

Обоснованность аргумента о невозможности столь длительного существования елшанской керамической традиции, весьма слабо меняющейся во времени, представляется нам вполне справедливой. Причем еще меньшую степень корректности, чем поздние даты, имеет ранняя группировка радиоуглеродных определений. Поскольку их количество практически в два раза меньше. К тому же они оторваны интервалом «безвременья» от периода 5875-5250 cal ВC. Кроме того, специалисты значительно больше причин видят для удревнения радиоуглеродных датировок керамики, в то время как эффект «омоложения» связывают только с загрязненностью современной органикой. Для устранения подобного загрязнения разработана достаточно эффективная методика, тогда как влияние «резервуарных эффектов» различного рода, «удревняющих» датировку, до сих пор относится к предметам изучения, и их перечень постоянно пополняется.

Следует отметить, что именно ранняя группа дат прибавляет к бытованию елшанской традиции практически 900 калиброванных лет, доводя период ее существования до двух тысяч лет, в то время как поздняя группа дат характеризуется большей компактностью.

Как известно, ранние даты представлены материалами стоянок Ивановка, Чекалино IV и Большая Рaковка II. При этом практически все радиоуглеродные определения по неолитической керамике стоянки Ивановка датируются значительно более ранним временем, чем аналогичные материалы с других памятников лесостепного Заволжья. Елшанская керамика Ивановской стоянки древнее основного массива ел- шанских дат на 600-1000 радиоуглеродных лет, керамика средневолжской культуры с накольчатым орнаментом - от 500 до 1000 лет, средневолжская керамика, украшенная длинным гребенчатым штампом в среднем древнее на 500 лет [13, табл. 1]. Наличие подобных аномальных отклонений, видимо, вызвано каким-то локальным «резервуарным эффектом», отрицание которого приводит нас к выводу, что на протяжении всего неолита ивановское население являлось бессменным генератором новых керамических традиций для всего лесостепного Заволжья, опережая своих соседей в развитии данных традиций на 500, а то и 1000 лет.

Подобный «резервуарный эффект» может объясняться тем, что обитатели Ивановской стоянки варили в глиняной посуде рыбу или пресноводных моллюсков, которые в процессе жизнедеятельности накапливали в своих тканях более древней углерод. При приготовлении пищи этот углерод проникает в тесто керамики, что приводит к удревнению радиоуглеродных датировок [10, с. 37]. Примечательно, что находки раковин моллюсков отмечены в слое ряда елшанских стоянок: Чекалино IV, Ильинка и Лебяжинка IV, где, по всей видимости, они использовались в пищу.

Скорее всего «резервуарные эффекты» подобного рода привели и к удревнению ранних радиоуглеродных определений образцов керамики со стоянок Чекалино IV и Большая Раковка. Поскольку маловероятно, что население, ориентированное на расселение по берегам водоемов, не использовало в своем рационе питания рыбу и речных моллюсков, то «резервуарные эффекты» обязательно должны иметь место. Их отсутствие возможно в том случае, если эффект «жесткой воды» не зафиксирован в том водоеме, из которого добывались моллюски и рыба. Однако наличие на стоянке Чекалино IV речных раковин со следами антропогенного воздействия [14, с. 23], которые датированы на 400-1000 радиоуглеродных лет, древнее, чем наиболее ранние образцы керамики, свидетельствует о наличии в окрестных водоемах воды, обогащенной древним углеродом.

Еще одной из причин удревнения радиоуглеродных датировок керамики может являться наличие карбонатов в глиняном тесте посуды [15, с. 160]. Между тем исследователи елшанских древностей неоднократно обращали внимание на заизвесткованность елшанских фрагментов посуды, что даже отмечалось в качестве одного из признаков ее большей древности в сравнении с неолитической керамики средневолжской культуры [16]. Следует отметить, что, по наблюдениям A.Е. Мамонова, елшанский слой стоянки Чекалино IV характеризуется значительным содержанием аутигенного карбоната кальция $[14$, с. 4$]$.

Удревнение образцов глиняной посуды также может быть вызвано содержанием в глине геологического углерода, часть которого окисляется при обжиге керамики, увеличивая таким образом ее радиоуглеродный возраст [15, с. 160]. И судя по тому, что с каждым годом число известных причин, ведущих к удревнению керамики, постоянно растет, вероятно, не все они в настоящее время поддаются учету. В сложившихся условиях остается надеяться только на то, что для большинства продатированных образцов величина «резервуарного эффекта» имеет минимальный характер. В пользу этого может свидетельствовать ярко выраженный максимум концентрации зна- 
чительного количества елшанских дат в пределах 5875-5250 cal BC, степень разброса которых в целом соответствует стандартному времени бытования гомогенной керамической традиции.

Необходимо отметить еще одно обстоятельство, которое вызывает определенные сомнения в корректности ранней группы елшанских дат. По мнению А.А. Выборнова, одним из надежных критериев, подтверждающим достоверность радиоуглеродных определений, является близкое значение дат по одному памятнику, полученных в разных лабораториях [8, c. 128-139]. Однако по стоянкам Чекалино IV и Большая Раковка радиоуглеродные даты разных лабораторий кардинально расходятся. Все даты, полученные в лаборатории Института археологии Украины (г. Киев), относятся к поздней группе (Чекалино IV 5000-4500 cal BC, Большая Раковка 5500-4250 cal $\mathrm{BC})$, а все даты из лаборатории Российского государственного педагогического университета им. А.И. Герцена (г. Санкт-Петербург) - к ранней (Чекалино IV 7000-5750 cal ВC, Большая Раковка 72505500 cal BC). Причем степень разброса ранних дат весьма велика. Если погрешность калиброванных значений киевских дат укладывается в период 500 лет, то у петербургских дат она составляет от 550 до 1000 лет (табл. 1).

При этом сравнение статистического распределения всего массива дат, полученных в данных лабораториях, показало (рис. 2), что существенная разница в определении возраста образцов имеет место только для двух выше названных стоянок, по всем остальным памятникам даты весьма близки. Только для стоянки Лебяжинка IV в петербургской лаборатории получена дата древнее киевской на 200 некалиброванных лет, а для Ивановки - на 120 лет моложе, однако калиброванные интервалы этих дат взаимно пересекаются с киевскими. В целом же получается, что из 13 петербургских дат только 5 характеризуются большей древностью. Подобный характер распределения дат свидетельствует, что указанные отклонения не могут объясняться разницей в методике названных лабораторий и, видимо, вызваны причинами субъективного характера.

Вопрос достоверности поздней группы елшанских дат увязывается К.М. Андреевым и А.А. Выборновым с хронологией средневолжской культуры, начальный этап сложения которой, по их мнению, иллюстрирует материалы Ивановской стоянки (табл. 2). Однако, как уже отмечалось ранее, радиоуглеродные даты по данной стоянке явно удревнены. Судя по графику (рис. 3) амплитуда распределения дат по накольчатой керамике стоянки Ивановка почти повторяет график максимальной концентрации дат елшанской культуры. Следует отметить, что на других стоянках лесостепного Заволжья накольчатая керамика датируется примерно в тех же пределах, что и посуда, украшенная зубчатым штампом. Однако на Ивановской стоянке между керамикой, украшенной наколами и гребенчатым штампом, имеется существенной хронологический разрыв. Поэтому нельзя исключать, что ивановская керамика, орнаментированная наколами, относится к елшанской культуре. В елшанский хронологический интервал вписываются и даты по керамике Ильинской стоянки, украшенной насечками. Предположение о культурно-хронологическом единстве керамического комплекса Ильинской стоянки в свое время высказывалось А.Е. Мамоновым [17, с. 92-105]. Довольно ранняя дата для сосуда, орнаментированного насечками, недавно по- лучена со стоянки Лебяжинка IV (5500-4900 cal BC) [18, табл. 1: 3].

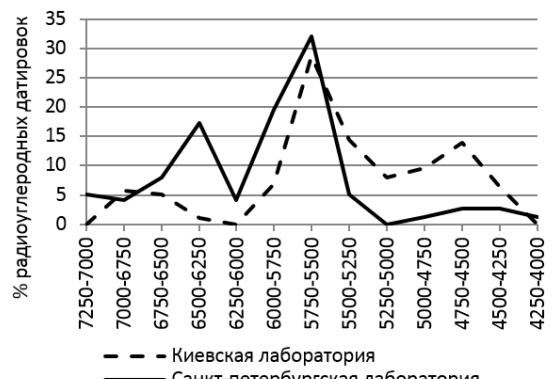

Рисунок 2 - График радиоуглеродных датировок керамики елшанской культуры, выполненных в киевской и санкт-петербургской лабораториях

Вопрос достоверности поздней группы елшанских дат увязывается К.М. Андреевым и А.А. Выборновым с хронологией средневолжской культуры, начальный этап сложения которой, по их мнению, иллюстрирует материалы Ивановской стоянки (табл. 2). Однако, как уже отмечалось ранее, радиоуглеродные даты по данной стоянке явно удревнены. Судя по графику (рис. 3) амплитуда распределения дат по накольчатой керамике стоянки Ивановка почти повторяет график максимальной концентрации дат елшанской культуры. Следует отметить, что на других стоянках лесостепного Заволжья накольчатая керамика датируется примерно в тех же пределах, что и посуда, украшенная зубчатым штампом. Однако на Ивановской стоянке между керамикой, украшенной наколами и гребенчатым штампом, имеется существенной хронологический разрыв. Поэтому нельзя исключать, что ивановская керамика, орнаментированная наколами, относится к елшанской культуре. В елшанский хронологический интервал вписываются и даты по керамике Ильинской стоянки, украшенной насечками. Предположение о культурно-хронологическом единстве керамического комплекса Ильинской стоянки в свое время высказывалось А.Е. Мамоновым [17, с. 92-105]. Довольно ранняя дата для сосуда, орнаментированного насечками, недавно получена со стоянки Лебяжинка IV (5500-4900 cal ВC) [18, табл. 1: 3].

На наш взгляд, данные материалы иллюстрируют процесс перерастания елшанских традиций в средневолжские, который проходил без существенного влияния со стороны орловской культуры [19, с. 119; 20, с. 87-89]. К.М. Андреев и А.А. Выборнов [12, c. 121] отрицают подобную возможность, аргументируя свою точку зрения тем, что орнаментация неолитической керамики имела сакральный характер и изменения в ее облике могли происходить только в результате взаимодействия с представителями других культур. Однако В.А. Шнирельман, специально изучавший данный вопрос по материалам гончарства у ряда африканских народов, задержавшихся в своем развитии, пришел к выводу, что изменение орнаментальных стилей порой происходило по причине того, что женщины, изготовлявшие глиняную посуду, просто не желали повторять одни и те же схемы орнамента [21, с. 26-27]. Противоречит представлениям о сакральности посуды и тот факт, что, судя по беспорядочному залеганию фрагментов и развалов сосудов в слое неолитических стоянок, к битой посуде относились как к обычному мусору, а это вряд ли допустимо по отношению к вещам из сферы сакрального мировосприятия. 
Таблица 2 - Радиоуглеродные даты памятников средневолжской культуры, выполненные по фрагментам керамики

\begin{tabular}{|c|c|c|c|c|c|c|c|c|c|}
\hline cal BC & $\begin{array}{c}6250- \\
6000\end{array}$ & $\begin{array}{c}6000- \\
5750\end{array}$ & $\begin{array}{c}5750- \\
5500\end{array}$ & $\begin{array}{c}5500- \\
5250\end{array}$ & $\begin{array}{c}5250- \\
5000\end{array}$ & $\begin{array}{c}5000- \\
4750\end{array}$ & $\begin{array}{c}4750- \\
4500 \\
\end{array}$ & $\begin{array}{c}4500- \\
4250 \\
\end{array}$ & $\begin{array}{c}4250- \\
4000 \\
\end{array}$ \\
\hline \multicolumn{10}{|c|}{ Ивановка } \\
\hline $7060 \pm 100$ & $\mathrm{XX}$ & $\mathrm{XX}$ & & & & & & & \\
\hline $7100 \pm 100$ & $\mathrm{xx}$ & $\mathrm{xx}$ & & & & & & & \\
\hline $6980 \pm 80$ & & $\mathrm{xX}$ & & & & & & & \\
\hline $6930 \pm 90$ & & $\mathrm{xx}$ & $\mathrm{x}$ & & & & & & \\
\hline $6840 \pm 90$ & & $\mathrm{xx}$ & $\mathrm{xx}$ & & & & & & \\
\hline $6100 \pm 90$ & & & & $\mathrm{x}$ & $\mathrm{xx}$ & $\mathrm{xx}$ & & & \\
\hline $6090 \pm 80$ & & & & & $\mathrm{xX}$ & $\mathrm{XX}$ & & & \\
\hline \multicolumn{10}{|c|}{ Ильинка } \\
\hline $6770 \pm 90$ & & $\mathrm{x}$ & $\mathrm{xX}$ & & & & & & \\
\hline $6670 \pm 100$ & & & $\mathrm{xx}$ & $\mathrm{x}$ & & & & & \\
\hline $5730 \pm 80$ & & & & & & & $\mathrm{xx}$ & $\mathrm{x}$ & \\
\hline $5620 \pm 80$ & & & & & & & $\bar{x}$ & $\mathrm{x}$ & \\
\hline $5500 \pm 100$ & & & & & & & & $x$ & $\mathrm{XX}$ \\
\hline \multicolumn{10}{|c|}{ Красный Яр VII } \\
\hline $5780 \pm 100$ & & & & & & $\mathrm{x}$ & $\mathrm{xx}$ & $\mathrm{x}$ & \\
\hline \multicolumn{10}{|c|}{ Лебяжинка IV } \\
\hline $5930 \pm 90$ & & & & & & $\mathrm{xx}$ & $\mathrm{xx}$ & & \\
\hline $5880 \pm 90$ & & & & & & $\mathrm{xx}$ & $\mathrm{xx}$ & & \\
\hline $6000 \pm 150$ & & & & & $\mathrm{xx}$ & $\mathrm{xX}$ & $\mathrm{xX}$ & & \\
\hline $5690 \pm 80$ & & & & & & & $\mathrm{xX}$ & $\mathrm{x}$ & \\
\hline $5590 \pm 80$ & & & & & & & $\mathrm{x}$ & $x$ & \\
\hline $5420 \pm 80$ & & & & & & & & $\mathrm{xX}$ & $\mathrm{xx}$ \\
\hline $5360 \pm 90$ & & & & & & & & $\mathrm{x}$ & $\mathrm{xX}$ \\
\hline $6020 \pm 90$ & & & & & $\mathrm{xx}$ & $\mathrm{xx}$ & & & \\
\hline \multicolumn{10}{|c|}{ Виловатое } \\
\hline $6320 \pm 90$ & & & & $\mathrm{xx}$ & $\mathrm{xX}$ & & & & \\
\hline $6020 \pm 90$ & & & & & $\mathrm{xx}$ & $\mathrm{xx}$ & & & \\
\hline $5840 \pm 90$ & & & & & & $\mathrm{xX}$ & $\mathrm{xX}$ & & \\
\hline $5840 \pm 100$ & & & & & & $\mathrm{XX}$ & $\mathrm{xX}$ & & \\
\hline $5910 \pm 80$ & & & & & & $\mathrm{XX}$ & $\mathrm{XX}$ & & \\
\hline $6160 \pm 100$ & & & & $\mathrm{X}$ & $\mathrm{XX}$ & $\mathrm{XX}$ & & & \\
\hline $5980 \pm 100$ & & & & & $\mathrm{xx}$ & $\mathrm{xx}$ & $\mathrm{x}$ & & \\
\hline $5920 \pm 90$ & & & & & & $\mathrm{XX}$ & $\mathrm{xx}$ & & \\
\hline $6010 \pm 80$ & & & & & $\mathrm{xx}$ & $\mathrm{xx}$ & & & \\
\hline $5880 \pm 90$ & & & & & & $\mathrm{xx}$ & $\mathrm{xX}$ & & \\
\hline $5960 \pm 80$ & & & & & & $\mathrm{xx}$ & $\mathrm{x}$ & & \\
\hline $5755 \pm 80$ & & & & & & & $\mathrm{xx}$ & $\mathrm{x}$ & \\
\hline \multicolumn{10}{|c|}{ Калмыковка I } \\
\hline $5950 \pm 120$ & & & & & $\mathrm{XX}$ & $\mathrm{xx}$ & $\mathrm{xx}$ & & \\
\hline $5989 \pm 70$ & & & & & & $\mathrm{XX}$ & & & \\
\hline сумма радиоуглеродных дат в \% & 2,8 & 10 & 6,17 & 3,5 & 12,2 & 23,7 & 21,6 & 10,66 & 4,7 \\
\hline
\end{tabular}

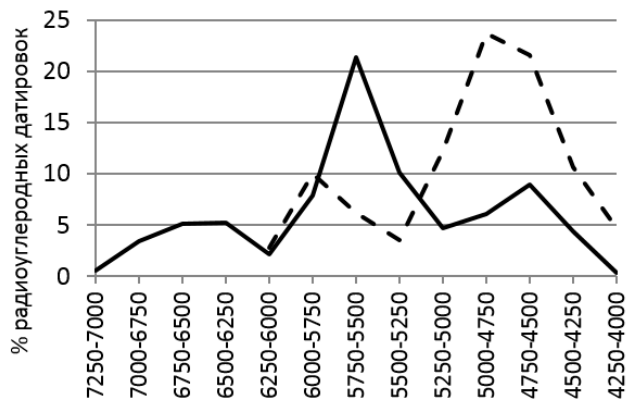

— Елшанская культура - - - Средневожская культура

Рисунок 3 - График радиоуглеродных датировок керамики елшанской культуры (линия синего цвета) и средневолжской культуры (линяя красного цвета)

Судя по графику соотношения радиоуглеродных елшанской и средневолжской культуры, средневолжская керамическая традиция приходит на смену елшанской на хронологическом отрезке 5500-5250 cal BC.
В заключение хотелось бы остановиться на вопросе о том, насколько статистическая модель радиоуглеродный хронология неолита лесостепного Заволжья соответствует существующему археологического контексту. Преимущества предложенной модели, прежде всего, заключаются в том, что она в большей степени соответствует нашим представлениям о длительности бытования керамической традиции. Всё течет, всё изменяется. Облик же елшанской керамики на всем протяжении существования культуры не претерпевает существенных изменений. Следовательно, данная традиция существовала на ограниченном отрезке времени, которому соответствует концентрация радиоуглеродных дат 5875$5250 \mathrm{cal} \mathrm{BC}$. Признание этого факта объясняет достаточно развитой облик елшанских керамических традиций и допускает возможность их появления в результате ограниченной инфильтрации среднеазиатского населения, поскольку устраняет теперешний хронологический приоритет елшанских древностей. 
О не раннем характере елшанских древностей свидетельствует и отщепово-пластинчатый облик их индустрии, не находящей близких аналогов в культурах мезолитического времени.

\section{Список литературы:}

1. Мамонов А.Е. О культурном статусе елшанских комплексов // Вопросы археологии Поволжья. Вып. 1. Самара: СГПУ, 1999. С. 15-43.

2. Мамонов А.Е. Новые материалы Ильинской стоянки в Самарской области // Историко-археологические изыскания. Вып. 5. Самара, 2002. С. 148-162.

3. Тимофеев В.И. Некоторые проблемы неолитизации Восточной Европы // Тверской археологический сборник. Вып. 5. Тверь: Триада, 2002. С. 209-214.

4. Мамонов А.Е. Елшанская культура // История Самарского Поволжья с древнейших времен до наших дней. Каменный век. Самара: СНЦ РАН, 2000. C. 147-176.

5. Вискалин А.В. К вопросу о датировке ранненеолитической керамики елшанского типа // Тверской археологический сборник. Вып. 6. Тверь: Триада, 2006. С. 260-264.

6. Вискалин А.В. О хронологии и периодизации ранних этапов неолита Волго-Уральской лесостепи // Самарский край в истории России. Вып. 3. Самара: Самарский областной историко-краеведческий музей, 2007. С. 4-13.

7. Шишлина Н.И., Хеджес Р.Е.М., Зазовская Э.П., Севастьянов В.С., Чичагова О.А. Резервуарный эффект и результаты датирования катакомбных культур Северо-Западного Прикаспия // Российская археология. 2007. № 2. С. 39-47.

8. Выборнов А.А. Неолит Волго-Камья. Самара: СГПУ, 2008. 490 c.

9. Выборнов А.А., Ковалюх Н.Н., Скрипкин В.В. К радиокарбоновой хронологии неолита Среднего Поволжья: западный регион // Российская археология. 2008. № 4. С. 64-71.

10. Зайцева Г.И., Скаковский Е.Д., Семенцов А.А., Лебедева Л.М., Бурова Н.Д., Ришко С.А. Химический состав углеродосодержащих компонентов неолитической керамики: первые итоги // Радиоуглеродная хронология эпохи неолита Восточной Европы VII-III тысячелетия до н.э. Смоленск, 2016. С. 32-37.
11. Выборнов А.А., Андреев К.М., Кулькова М.А., Филиппсен Б. Радиоуглеродная хронология неолита Волго-Камья // Уральский исторический вестник. 2018. № 3 (60). С. 66-77.

12. Андреев К.М., Выборнов А.А. Ранний неолит лесостепного Поволжья (елшанская культура). Самаpa, 2017. $270 \mathrm{c}$.

13. Выборнов А.А., Андреев К.М., Кулькова М.А., Нестеров Е.М. Радиоуглеродные данные к хронологии неолита лесостепного Поволжья // Радиоуглеродная хронология эпохи неолита Восточной Европы VII-III тысячелетия до н.э. Смоленск, 2016. С. 74-96.

14. Мамонов А.Е. Елшанский комплекс стоянки Чекалино IV // Древние культуры лесостепного Поволжья. Самара: СГПУ, 1995. С. 3-25.

15. Зазовская Э.П. Радиоуглеродное датирование: современное состояние, проблемы, перспективы развития и использование в археологии // Вестник археологии, антропологии и этнографии. 2016. № 1 (32). С. 151-164.

16. Васильев И.Б., Выборнов А.А. Неолит Поволжья. Куйбышев: КГПИ, 1988. 112 с.

17. Мамонов А.Е. Ильинская стоянка и некоторые проблемы неолита лесостепного Заволжья // Проблемы изучения раннего неолита лесной полосы Европейской части СССР. Ижевск: Удм. ИИЯЛИ УО AH CCCP, 1988. C. 92-105.

18. Андреев К.М., Выборнов А.А., Кулькова М.А. Новые радиоуглеродные даты комплексов неолитической керамики поселения Лебяжинка IV // Известия Самарского научного центра Российской академии наук. 2018. Т. 20, № 3-1. С. 203-207.

19. Ставицкий В.В. Керамические традиции елшанской культуры: происхождение и хронология // Евразия в кайнозое. Стратиграфия, палеоэкология, культура. 2014. № 3. С. 136-141.

20. Ставицкий В.В. Дискуссионные вопросы изучения ранненеолитических памятников Среднего Поволжья // Международный научно-исследовательский журнал. 2017. № 5-1 (59). С. 87-89.

21. Шнирельман В.А. Археологическая культура и социальная реальность (проблема интерпретации керамических ареалов) // Этнографо-археологические комплексы. Новосибирск: Наука, 2002. С. 19-38.

\title{
A STATISTICAL MODEL FOR THE RADIOCARBON CHRONOLOGY OF THE NEOLITHIC FOREST-STEPPE VOLGA REGION MONUMENTS
}

(C) 2018

\author{
Stavitsky Vladimir Vyacheslavovich, doctor of historical sciences, \\ professor of General History and Social Science Department \\ Penza State University (Penza, Russian Federation)
}

Abstract. The paper deals with the chronology of the early Neolithic forest-steppe Zavolzhye monuments, which
is based on radiocarbon definitions obtained from fragments of ceramics. Radiocarbon dates on Elshanskaya and
Srednevolzhskaya culture monuments are collected in two tables. They are graphically represented by a probability
interval for each date. For the conditional statistical unit the chronological interval of 125 years is accepted. On the
basis of statistical data, the author has constructed graphs that reflect the frequency of dates occurrence for periods of
250 years. As for the Elshanskaya culture monuments the highest concentration of radiocarbon dates occurs on a
chronological segment $5875-5250$ cal BC ( $39 \%$ of all dates). Half of the dates are recorded on the segment $4750-$
4500 cal BC ( $21 \%)$. Only $12 \%$ of radiocarbon dates are in $6750-6250$ cal BC, which belongs to the period of the El-
shanskaya antiquities development. In our opinion, Elshanskaya culture could not exist unchanged for such a long
time. Such a significant variation in time is apparently due to the imperfection of the dating method and the presence
of «reservoir effects» of various kinds. Elshanskaya culture probably existed in $5875-5250$ cal BC. At the final stage of
Elshanskaya antiquities existence (5500-5250 cal BC) the monuments of Srednevolzhskaya culture started to develop.
Keywords: early Neolithic; Elshanskaya culture; Srednevolzhskaya culture; forest-steppe Volga region; radiocar-
bon chronology; reservoir effect; Neolithic ceramics; statistical model; periods of Elshanskaya antiquities; verifica-
tion; calibrated dates; sacred ceramics; archeological context. 